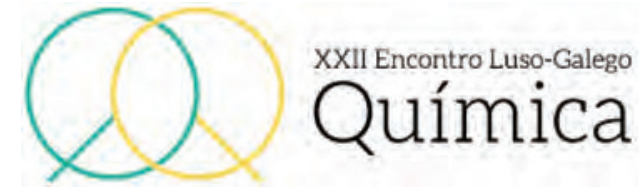

\section{Encontro Luso-Galego de Química}

O XXII Encontro Luso-Galego de Química (http:// xxiilgq.eventos.chemistry.pt/) surgiu na sequência dos encontros anteriores realizados desde 1985, alternadamente em Portugal e Espanha, decorrentes da estreita relação existente entre a Sociedade Portuguesa de Química e o Colegio Oficial de Químicos de Galicia. A edição de 2016 decorreu no Instituto Politécnico de Bragança entre os dias 9 e 11 de novembro de 2016.

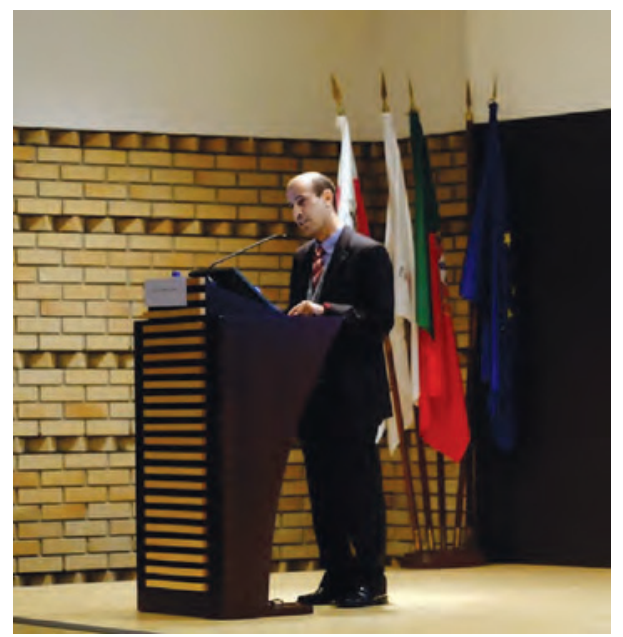

límeros; Química e Ambiente; Química e Saúde; Química-Física; Química Industrial e Engenharia; Química Inorgânica; Química Orgânica; Química Verde.

O XXII Encontro Luso-Galego de Química contou com 322 participantes, oriundos maioritariamente de Portugal e Espanha, que contribuíram para um programa científico de alto nível, composto por 5 lições plenárias proferidas por investigadores de renome internacional, 129 comunicações orais distribuídas por 30 sessões em paralelo e 145 comunicações em painel distribuídas por 4 sessões, totalizando 274 trabalhos (programa científico detalhado disponível em http://xxiilgq.eventos.chemistry.pt/images/Programa_ Cientifico_Detalhado_PT_final_2.pdf).

O Encontro manteve a sua estrutura habitual, sendo o arranque dos trabalhos de cada período marcado por lições

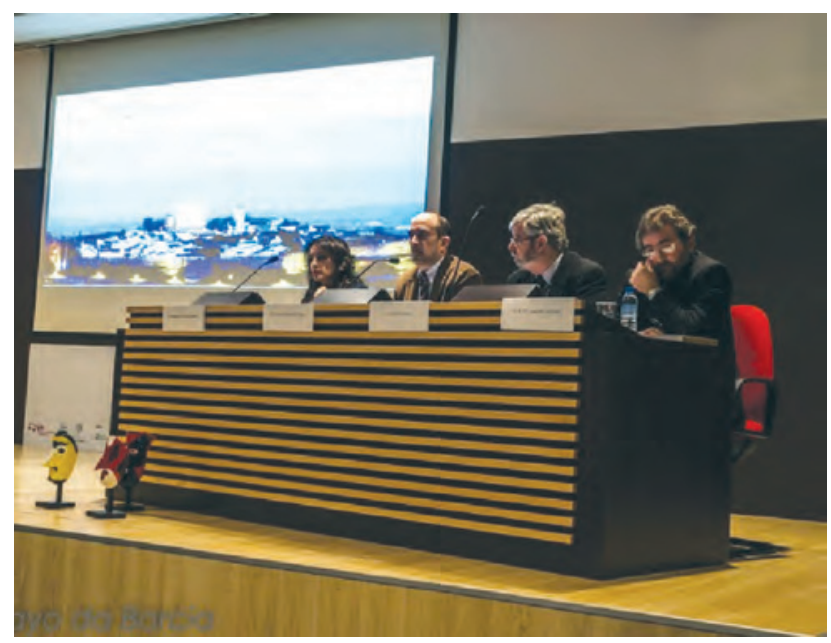

Sessão de Abertura do XXII Encontro Luso-Galego de Química

Este evento tem por objetivo o intercâmbio científico e tecnológico entre Portugal e a Galiza, visando fomentar a troca de conhecimentos e de experiências entre investigadores e profissionais dos meios académico e industrial a trabalhar em química e engenharia química. O XXII Encontro incluiu no seu programa catorze áreas científicas: Bioquímica e Biotecnologia; Catálise; Educação e Ensino da Química; Nanoquímica e Nanotecnologia; Química Agro-Mar-Alimentar; Química Analítica; Química dos Po- plenárias sobre temas atuais e emergentes. No primeiro dia tiveram lugar as lições plenárias do Prof. Mario Ferruzzi, da North Carolina State University (Plant phenolics as a tool to modify glycemic response of foods) e do Prof. Francisco Guitian, da Universidade de Santiago de Compostela (Biocerámicas y química: de la ciencia básica a la industria). O segundo dia iniciou com a lição plenária do Prof. João Mano, da Universidade de Aveiro (Designing hydrogels using natural-based polymers for biomedical ap-

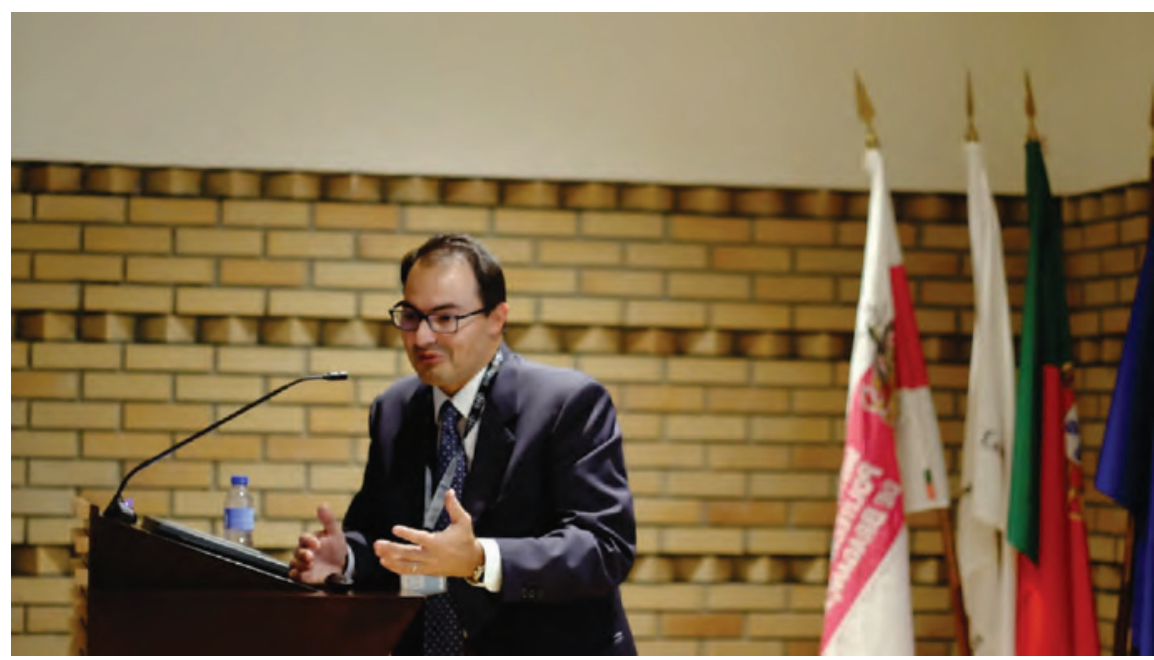

Lição Plenária do Prof. Mario G. Ferruzzi no XXII Encontro Luso-Galego de Química 
plications), tendo continuado pela tarde com a contribuição do Prof. Diego Moldes, da Universidade de Vigo (Biomasa lignocelulósica: una fuente de productos para la Química Verde). O arranque do último dia do Encontro foi marcado pela lição plenária do Prof. João Crespo, da Universidade Nova de Lisboa (Membrane engineering ...... What else?).

Realçamos ainda o número significativo de apresentações orais proferidas por jovens investigadores envolvidos em estudos de mestrado e de doutoramento, muitos deles a realizar a sua primeira apresentação oral num evento científico, uma das marcas que caracterizam os Encontros Luso-Galegos de Química. A elevada qualidade do programa científico, aliada ao acolhedor programa social, que incluiu uma receção de São Martinho e o tradicional Jantar do Encontro, permitiu criar um ambiente bastante agradável entre os participantes durante os 3 dias de reunião, propiciador da desejada troca de conhecimentos e experiências e do estabelecimento, ou fortalecimento, de colaborações.

De destacar, por fim, a realização pela primeira vez de um Encontro Luso-Galego de Química no Instituto Politécnico de Bragança, correspondida por uma elevada participação e submissão de trabalhos. Na ótica da Comissão Organizadora, a apreciação final é bastante positiva, pelo que se pode afirmar que foram concretizados os objetivos propostos inicialmente para o evento. Gostaríamos de dirigir uma palavra final de agradecimento a todas as pessoas envolvidas nas diversas comissões e aos patrocinadores pelo apoio concedido.

A Comissão Organizadora

\section{Atualidades Científicas}

\section{Produção eficiente de hidrogénio}

A eletrólise da água com vista à produção de hidrogénio e como sistema altamente eficiente de armazenamento de energia tem atraído um grande interesse por parte da comunidade científica. Em particular, eletrolisadores de óxido sólido, SOECs (Solid Oxide Electrolysis Cells), têm recebido considerável atenção em virtude da sua elevada eficiência. No entanto, os SOECs que usam elétrodos convencionais possuem problemas de desempenho devido a delaminação, estabilidade redox e degradação dos elétrodos durante a eletrólise.

Recentemente, uma equipa de investigadores liderada por Guntae Kim da Ulsan National Institute of Science and

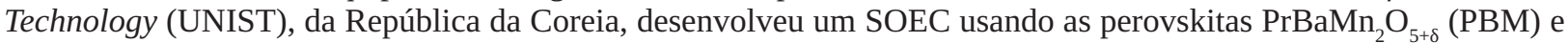
$\mathrm{PrBa}_{0.5} \mathrm{Sr}_{0.5} \mathrm{Co}_{1.5} \mathrm{Fe}_{0.5} \mathrm{O}_{5+\delta}$ (PBSCF50) como elétrodos. O sistema estudado mostrou ser altamente eficiente na produção de hidrogénio sem degradação observável dos elétrodos por um período superior a $600 \mathrm{~h}$.

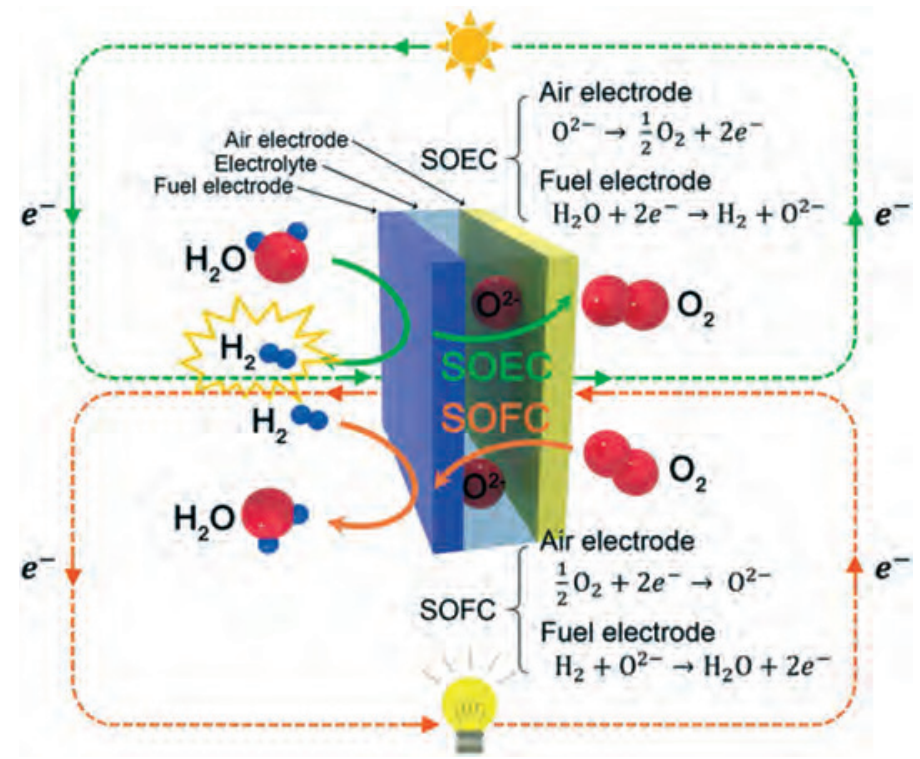

Fontes:

Efficient Hydrogen Production, http://www.chemistryviews.org/details/ezine/9891941/Efficient_Hydrogen_Production.html?elq_mid=12498\&elq_cid=3605105 (Acedido em 25/10/2016)

A. Jun, J. Kim, J. Shin, G. Kim. Achieving High Efficiency and Eliminating Degradation in Solid Oxide Electrochemical Cells Using High Oxygen-Capacity Perovskite. Angew. Chem. Int. Ed. 55 (2016) 12512-12515. DOI: 10.1002/anie.201606972

Paulo Mendes

(pjgm@uevora.pt) 